\title{
Fatigue Behaviour of Aluminum Alloy at Elevated Temperature
}

\author{
Farhad B. Bahaideen \\ School of Mechanical Engineering, Universiti Sains Malaysia \\ 14300 Nibong Tebal, Penang, Malaysia \\ E-mail: farhadbilal62@yahoo.com \\ Ahmed M. Saleem \\ Technical College, Mosul, Iraq \\ E-mail: ah_ms1971@yahoo.com \\ Khaleed Hussain M.T (Corresponding Author) \\ School of Mechanical Engineering, Universiti Sains Malaysia \\ 14300 Nibong Tebal, Penang, Malaysia \\ E-mail:Khalid_tan@rediffmail.com \\ Zaidi Mohd. RIPIN \\ School of Mechanical Engineering, Universiti Sains Malaysia \\ 14300 Nibong Tebal, Penang, Malaysia \\ E-mail: mezaidi@eng.usm.my \\ Zainal arifin ahmad
}

School of Materials ans Mineral Resources Engineering, Universiti Sains Malaysia

14300 Nibong Tebal, Penang, Malaysia

Zahurin Samad

School of Mechanical Engineering, Universiti Sains Malaysia

14300 Nibong Tebal, Penang, Malaysia

E-mail: zahurin@eng.usm.my

Nur Azam Badarulzman

School of Mechanical and manufacturing Engineering, Universiti Tun Hussein Onn Malaysia

86400Parit Raja, Johor, Malaysia

\begin{abstract}
In this article fatigue behavior of aluminum alloy at elevated temperature is studied. Fatigue failure is a major failure mode of failure where the cyclic load is applied to the machine element. Hence certainly it is important to know the fatigue behavior of the machine element at elevated temperature, aluminum alloy is excessively used in industry like in aerospace automobile and miniatures industries etc, because of it $\mathrm{s}$ non corrosive property and light in weight. The fatigue behavior of 2024 - T4 Aluminum alloy is investigated under room and elevated temperatures and it is observed that the fatigue strength of 2024 - T4 Aluminum alloy at elevated temperature is reduced by a factor $1.2-1.4$ compared with dry fatigue strength.
\end{abstract}

Keywords: Dry fatigue, Elevated fatigue, Aluminum, Aerospace

\section{Introduction}

The increasing use of engineering materials in severe environments requires that the materials have good mechanical properties in these environments. Fatigue is one of the principle damage mechanisms for materials operating at elevated temperatures. Fatigue at elevated temperature produces larger strain deformation, crack initiation and growth. Finally the material or structure may fail in different modes, fatigue, rupture, loss and large deformation etc.... For the material under elevated fatigue there is serious influence on the properties and fatigue life of the material $(\mathrm{H}$. Mao and $\mathrm{S}$. 
Mahadevan, 2000).Figure 1 Fracture of an Aluminium Crank Arm. Dark area: slow crack growth. Bright area: sudden fracture.Damage initiation and propagations properties for aluminum alloys structures is increased with elevated temperature fatigue compared with dry fatigue (Bilal M. Ayuub et al, 2002). This investigation was initiated with the objective of fatigue and the effect of elevated temperatures on the fatigue resistance and fatigue properties. The behavior of aluminum alloy 2024 T4 was tested under dry fatigue and elevated fatigue in order to compare the characteristics of this alloy in the both conditions. This paper discusses the behavior of damage accumulation in dry and elevated fatigue (T. Hanlon, et al, 2005).

\section{Parameter for non-linear region:}

1) Strength

2) Ductility

3) Strain Hardening properties

The flow properties of a metal may be greatly altered by repeated plastic strains.

2.1 A metal deformation resistance may increase cyclic hardening and the stress required to enforce the strain limit on successive reversals increases. In general annealed metals and aluminum is decreases cyclic softening. The stress required to enforce the strain limit decreases with successive reversals. In general cold worked metals having unchanged cyclic stability.

\subsection{The ideal fatigue resistant material for structural applications could be achieved with the following characteristics}

1) A strain hardening exponent of about 0.1 to insure cyclic stability.2) A high fracture strength to resist the imposed loads3) High fracture ductility to accommodate large plastic strains at critical locations (notches, inclusions, voids, etc.).

\subsection{Increased strength is not necessarily synonymous with increased fatigue resistance.}

1) In light of the large changes in flow properties that may result from cycling, it should not be surprising that monotonic fracture properties are more indicative of a metal's fatigue resistance than either yield or ultimate strength.2) Monotonic fracture properties are sensitive to many of the internal defects which are known to affect fatigue behavior (predicted by sigma-f and ef values).

\subsection{Total strain resistance}

1) Metal's resistance to total strain cycling summation of elastic and plastic strain resistance is given by equation. $($ Tot strain $\mathrm{amp} / 2)=($ Elastic strain $\mathrm{amp} / 2)+($ Plastic strain $\mathrm{amp} / 2)$.

$$
=\left(\operatorname{Sigma}-\mathrm{f}^{\prime} / \mathrm{E}\right)(2 \mathrm{Nf})^{\wedge}(\mathrm{b})+\mathrm{ef}^{\prime}(2 \mathrm{Nf})^{\wedge}(\mathrm{c})
$$

At short lives the plastic strain component predominates importance of ductility. At long lives the elastic component predominates role of strength. Transition fatigue life, $2 \mathrm{Nt}$ life where the total strain amplitude consists of equal elastic and plastic component.Whereas, 2Nt varies $1 \mathrm{e} 5$ reversals at low hardness normalized steel will display appreciable plastic strain even at very long lives.In 10 reversals at the highest hardness, highly strengthened steels resist cyclic strains largely on the basis of strength over the entire life range.Rule of thumb is that most metals when subjected to a strain amplitude of 0.01 will fail in approximately 2000 reversals. Consideration of local stress-strain response suggests that in many engineering structures the material at the critical location experiences essentially reversed strain cycling, thus emphasizing the importance of strain-based fatigue data. Total strain cycling resistance will depend on a high (ef)' at short lives, a high sigma-f' at long lives, and a combination of high strength and ductility at intermediate lives.

\section{Literature Survey:}

H. Moa and S. Mahadevan (H. Mao and S. Mahadevan, 2000) derived probabilistic model for the reliability analysis of the creep and fatigue of materials based on experimental data and a linear damage accumulation rule was used. The main concluded remarks were that the scatter of different random variables on the creep fatigue life is very important.

Bilal M. Ayuub etal (Bilal M. Ayuub et al, 2002) studied the fatigue behavior of material structures subjected to fatigue loadings under the effect of sea water waves and sea environment. The objective of this paper was to develop reliability based methods for determining the fatigue life of structural details associated with conventional displacement type surface monohull ships based on the $\mathrm{S}-\mathrm{N}$ approach and on the assumption that the fatigue damage accumulation is a linear phenomenon (i.e; that follows Miner's rule).

T. Hanlon, E. D. Tabahnikova, and S. Suresh (T. Hanlon, et al, 2005) studied the stress - life fatigue behavior and fatigue crack growth characteristics of pure Ni were studied as a function of grain size. This study concluded that the fatigue resistance of engineering structures by recourse to grain refinement down to the nanocrystalline regime. 
Levon Minnetyan (Levon Minntyan, 2005) studied damage progression sequence during different degradation stages was made. This study showed that the number of cycles to failure at different temperatures using computational simulation data in the assessment of damage tolerance.

Ali F. Hamide Al - amiri (Ali F. Hamide Al - Amiri, 2006) studied the fatigue behavior of Aluminum alloy at elevated temperature was investigated using random cyclic loading at zero mean stress. The results showed that the mechanical and fatigue properties are decreased at elevated temperature compared with the results of dry fatigue.

Svjetlana Stekovic (Svjetlana Stekovic, 2007) investigated high strength nickel - base super alloys have been used under dry and elevated fatigue (high temperature). The focus of this work was on a study of the low cycle fatigue and thermo mechanical fatigue behavior of a polycrystalline. The main conclusions were that the presence of the coatings was, in most cases, detrimental to low cycle fatigue lives of the super alloys at $500{ }^{\circ} \mathrm{C}$ while the coatings do improve the low cycle fatigue lives of the super alloys at $900{ }^{\circ} \mathrm{C}$.

\section{Experimental Work:}

\section{Material:}

Aluminum alloy specimen is taken as sample article and the average of chemical composition for three specimens is analyzed and compared them with the standard specification as shown in table (1).

Tensile test machine of maximum capacity $(1000 \mathrm{kN})$ is used to determine the mechanical properties of the material as per the standard Germany specification (DIN 5025) and compared with the standard specification as shown in table (2).The standard material specification for Aluminum 2024 alloy has given in table (3).

\section{Test Rig:}

Rotating bending test machine: A cantilever type, load controlled type machine of constant load ratio of (-1) is used for experimental work. The specimen is subjected to load at its free end perpendicular to its axis while rotating. This will develop a bending moment which can be calculated by using the following equations:

$$
\begin{gathered}
\sigma_{b}=M Y / I \\
\sigma_{b}=P^{*} L /\left(\pi * d^{3} / 32\right)
\end{gathered}
$$

Where:

$\mathrm{L}:$ Arm of the applied force $(\mathrm{L}=125.7 \mathrm{~mm})$

$\sigma_{b}:$ Bending stress

$Y:$ Radius of the specimen $=\mathrm{d} / 2$

$I$ : Moment of inertia $=\pi \mathrm{d}^{4} / 64$

The specimen dimensions are given in figure (1).

\section{Experimental Results and Discussion:}

Table (4) shows the $\mathrm{S}-\mathrm{N}$ curve fatigue data for specimens tested reversed bending and $(\mathrm{R}=-1$, stress ratio) at room temperatures. It is observed that as the applied bending stress is increases the life cycle of the specimen is go on decreased for the all the three group of specimen. It is generally accepted that as the applied stress is go on increases the life cycle of the material decreases, hence it is observed that for a different group of materials, the fatigue life varies as applied stress varies.

Figure (2) shows nature of curve for applied stress to the number cycle, it observed from the graphe that as decrease in applied stress range the life cycle is go on decreases. This curve shows the relationship between bending stress at failure and number of fatigue cycle. In this study 21 specimens have been tested and computed the life cycle for each specimen for various stress range for three groups of materials. From figure (2) it is observed that the curve is exponentially decreases, hence from this curve the equation for fatigue life of the $\mathrm{S}-\mathrm{N}$ curve is obtained as equation (3).

$$
\sigma_{f}=1479 *\left(N_{f}\right)^{-0.147}
$$

Similarly 21 specimens at different stress range are tested for three groups of materials at elevated temperature as 180 ${ }^{\circ} \mathrm{C}$. The loading condition is as applied to specimens at room temperature. It is observed from the table (5) is that as the 
stress range increases the fatigue life go on decreases as in the specimen tested in room temperature it also observed that at elevated temperature the life cycle is comparatively less for same loading condition applied to the specimen at room temperature for all three groups...

Figure (3) shows the behavior of the AL - alloy under high temperatures. It is evident that the life cycle goes on increases exponentially as decreasing in the stress range, hence from the curve, the equation of life of the $\mathrm{S}-\mathrm{N}$ curve is developed as (4).

$$
\sigma_{f}=524 *\left(N_{f}\right)^{-0.0858}
$$

Figure (4) shows a comparison between the $\mathrm{S}-\mathrm{N}$ curve for dry fatigue and elevated temperature.

It is evident that specimen at elevated temperature is having less life cycle as compared to the specimen tested at room temperature for the same loading conditions. Al - Kaisee (Rasha Hussam AL - Kiasee, 2002) studied the 2024 AL alloy material and a comparison between the published result and the current result is given in figure (5).

AL - Amiri (Ali F. Hamide Al - Amiri, 2006), Yaseen (Yassen Mohammed Kalook, 2007), and AL - Naimy (W. R. Al - Naimy, 1997) studied the $2024 \mathrm{AL}$ - alloy material and a comparison between the published result and the current result is given in figure (6).

\section{Conclusions}

In this study the fatigue life cycle of the for AL- Alloy 2024 - T4 is carried out for three group of materials for the different stress range, this specimen have been tested at room temperature and elevated temperature that is $180{ }^{\circ} \mathrm{C}$ and it observed that the life cycles are significantly reduce at elevated temperature comparative to specimen tested at room temperature at same applied stress range. The equations have developed for fatigue life for AL- Alloy $2024-\mathrm{T} 4$ at room temperature and elevated temperature. It is observed that the fatigue strength in elevated temperature is reduced compared to ambient temperature by a factor 1.2-1.4.

1) The fatigue behaviour of the AL - Alloy 2024 - T4 of dry fatigue at constant amplitude load may be described by the following formula:

$$
\sigma_{f}=1479 *\left(N_{f}\right)^{-0.147}
$$

2) While the behaviour of the AL- Alloy under $180^{\circ} \mathrm{C}$ may be taken the formula:

$$
\sigma_{f}=524 *\left(N_{f}\right)^{-0.0858}
$$

3) The fatigue strength under elevated temperature is reduced by a factor of $1.2-1.4$ compared with the strength at dry fatigue.

$\begin{array}{ll}\text { Abbreviations } & \\ L & \text { Arm of the applied force }(\mathrm{L}=125.7 \mathrm{~mm}) \\ \sigma_{b} & \text { Bending stress } \\ Y & \text { Radius of the specimen } \\ I & \text { Moment of inertia } \\ R & \text { Stress ratio } \\ \sigma_{f} & \text { Fatigue stress } \\ N_{f} & \text { Fatigue Life } \\ S & \text { Stress Range } \\ N & \text { Number of Cycle }\end{array}$

\section{References}

Ali F. Hamide Al - Amiri. (2006). "Cumulative Fatigue Damage Application to Estimating Parts Under High Temperature with Using Learning System", Ms. C. Thesis, Department of Technical Education, University of Technology, Iraq.

Bilal M. Ayuub et al. (2002). "Reliability - Based Design Guide lines for Fatigue of Ship Structures", The American Society of Naval Engineers Journal,. 
H. Mao and S. Mahadevan. (2000). "Creep Fatigue Reliability of High Temperature Materials", $8^{\text {th }}$ ASCE Specially Conference on Probabilistic Mechanics and Structural Reliability,

Levon Minntyan. (2005). "Computational Simulation of Composite Structural Fatigue”, NASA Glenn Research center,

Rasha Hussam AL - Kiasee. (2002). "Effect of Pipe - Stress on Al - Alloy Structural Fatigue life", Ph. D. Thesis, Mechanical Engineering Department, University of Technology, Iraq,.

Svjetlana Stekovic. (2007 ). "Low Cycle Fatigue and Thermo - Mechanical Fatigue of Uncoated and Coated Nickel Base Super alloys", Ph. D. Thesis, Linkoping University, Sweeden,.

T. Hanlon, et al. (2005). "Fatigue Behavior of Nonocrystalline Metals and alloys", International Journal of Fatigue, Vol. 27, pp. $1147-1158$.

W. R. Al - Naimy. (1997). "Cumulative Multi axial Fatigue Damage on Aircraft Alloy 2024 - T4 Under complex Loading”, M. Sc. Thesis, Mechanical Engineering Department, University of Technology,.

Yassen Mohammed Kalook. (2007). "The concept of cumulative fatigue damage as a tool to elevate the residual stresses for 2024 - Al alloy", Journal of Engineering and Technology.

Table 1. Experimental chemical composition for 2024 - T4 AL- alloy

\begin{tabular}{|c|c|c|c|c|}
\hline Element & $\mathrm{Cu}$ & $\mathrm{Mg}$ & $\mathrm{Mn}$ & $\mathrm{Si}$ \\
\hline$\% \mathrm{wt}$ & 4 & 0.244 & 0.43 & 0.12 \\
\hline Element & $\mathrm{Fe}$ & $\mathrm{Ni}$ & $\mathrm{Zn}$ & $\mathrm{Al}$ \\
\hline$\% \mathrm{wt}$ & 0.28 & 0.1 & 0.43 & 94.396 \\
\hline
\end{tabular}

Table 2. Experimental mechanical properties

\begin{tabular}{|c|c|c|c|c|}
\hline AL - alloy & $\sigma_{y}$ & $\sigma_{\text {ult }}$ & Elong. \\
(Mpa.) & (Mpa.) & Hardness \\
(Brinell)
\end{tabular}


Table 3. Standard material specification 2024 - T4 AL - alloy ${ }^{[3], ~[4] . ~}$

Chemical composition $(\% \mathrm{w})=$

Al 92.05; Cu 4.5; Mn 0.6; Cr 0.1; Mg 1.5; Zn 0.25; Si 0.5; fe 0.5

\begin{tabular}{|l|c|}
\hline Physical properties & \\
\hline Melting Range $\left({ }^{\circ} \mathrm{C}\right)$ & $502-638$ \\
\hline Density $\left(\mathrm{kN} / \mathrm{m}^{3}\right),\left(20{ }^{\circ} \mathrm{C}\right)$ & 1.366 \\
\hline Thermal Expansion $\left(1 /{ }^{\circ} \mathrm{C} * 10^{-6}\right)$ & $24.66\left(20-300{ }^{\circ} \mathrm{C}\right)$ \\
\hline
\end{tabular}

\begin{tabular}{|l|c|}
\hline Mechanical properties - temperature $=\mathrm{HT}$ & 482.3 \\
\hline Tensile strength $\left(\mathrm{MN} / \mathrm{mm}^{2}\right)$ & 344.5 \\
\hline Yield strength $\left(\mathrm{MN} / \mathrm{mm}^{2}\right)$ & 18 \\
\hline Elongation (\%) & 120 \\
\hline Hardness (Brinell) & 69.3 \\
\hline Elastic modulus (Gpa.) / tension & \multicolumn{2}{|c|}{} \\
\hline
\end{tabular}

Table 4. S - N curve fatigue data for 2024 - T4 AL- alloy at room temperatures.

\begin{tabular}{|c|c|c|c|}
\hline$\sigma_{\mathrm{b}}($ bending stress) Mpa & \multicolumn{2}{|c|}{ Life to failure (cycles) $\left(\mathrm{N}_{\mathrm{f}}\right)$} \\
& Group One & Group Two & Group Three \\
\hline 140 & $9.4^{*} 10^{6}$ & $8.2^{*} 10^{6}$ & $10.1^{*} 10^{6}$ \\
\hline 160 & $3.5^{*} 10^{6}$ & $4 * 10^{6}$ & $3.7^{*} 10^{6}$ \\
\hline 170 & $2.65^{*} 10^{6}$ & $3.01^{*} 10^{6}$ & $2.88^{*} 10^{6}$ \\
\hline 180 & $1.94 * 10^{6}$ & $1.77^{*} 10^{6}$ & $1.82^{*} 10^{6}$ \\
\hline 200 & $9.25^{*} 10^{5}$ & $8.88^{*} 10^{5}$ & $9.2^{*} 10^{5}$ \\
\hline 250 & $3.2^{*} 10^{4}$ & $3.07^{*} 10^{4}$ & $2.92^{*} 10^{4}$ \\
\hline 300 & $4.2^{*} 10^{3}$ & $4 * 10^{3}$ & $3.87^{*} 10^{3}$ \\
\hline
\end{tabular}


Table 5. S - N curve fatigue data for $2024-\mathrm{T} 4 \mathrm{AL}-$ alloy at $\left(180^{\circ} \mathrm{C}\right)$.

\begin{tabular}{|c|c|c|c|}
\hline$\sigma_{\mathrm{b}}($ bending stress) & \multicolumn{3}{|c|}{ Life to failure (cycles) $\left(\mathrm{N}_{\mathrm{f}}\right)$} \\
\hline Mpa & Group Four & Group Five & Group Six \\
\hline 140 & $5.2 * 10^{6}$ & $4.45^{*} 10^{6}$ & $4.9 * 10^{6}$ \\
\hline 160 & $1.1 * 10^{6}$ & $0.9 * 10^{6}$ & $1.07 * 10^{6}$ \\
\hline 170 & $8.1 * 10^{5}$ & $9.02 * 10^{5}$ & $8.4^{*} 10^{5}$ \\
\hline 180 & $5 * 10^{6}$ & $4.45^{*} 10^{5}$ & $5.07 * 10^{5}$ \\
\hline 200 & $1.2 * 10^{5}$ & $1.09 * 10^{5}$ & $1.7 * 10^{5}$ \\
\hline 250 & $1.2 * 10^{4}$ & $1.09 * 10^{4}$ & $1.11 * 10^{4}$ \\
\hline 300 & $1.2 * 10^{3}$ & $0.9 * 10^{3}$ & $0.85 * 10^{3}$ \\
\hline
\end{tabular}

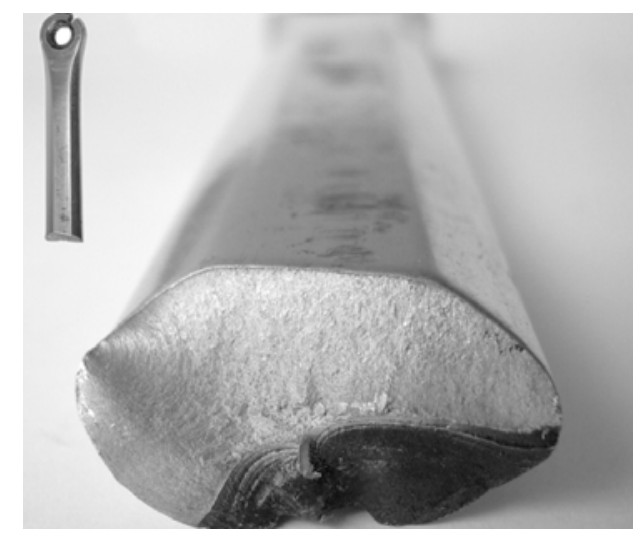

Figure 1. Fracture of an Aluminium Crank Arm. Dark area: slow crack growth. Bright area: sudden fracture

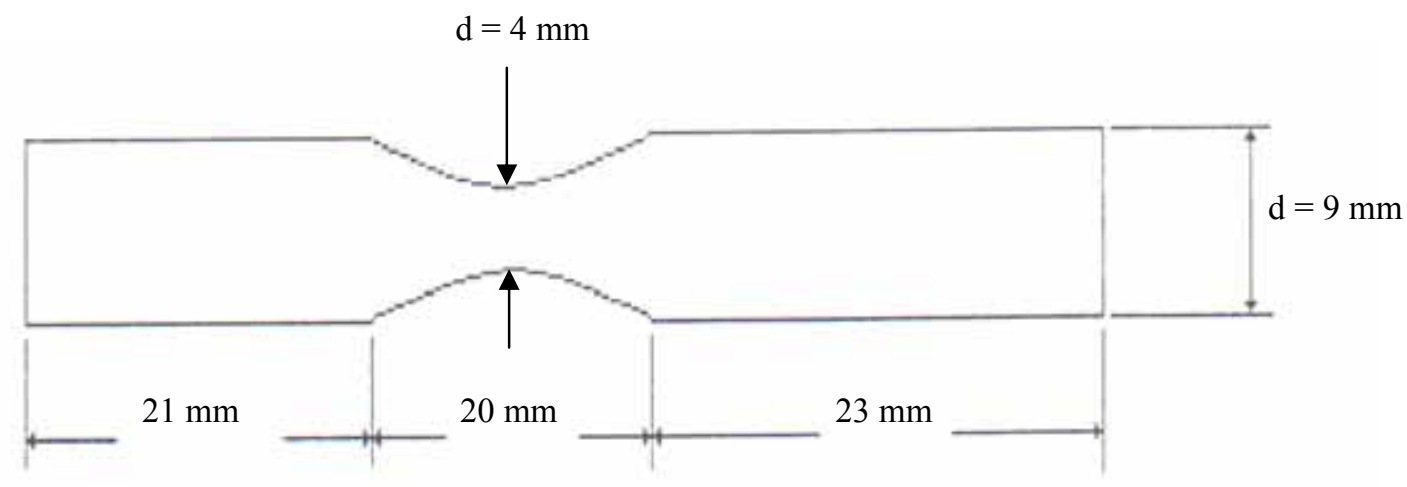

Figure 2. Dimensions of rotating bending fatigue test specimens 


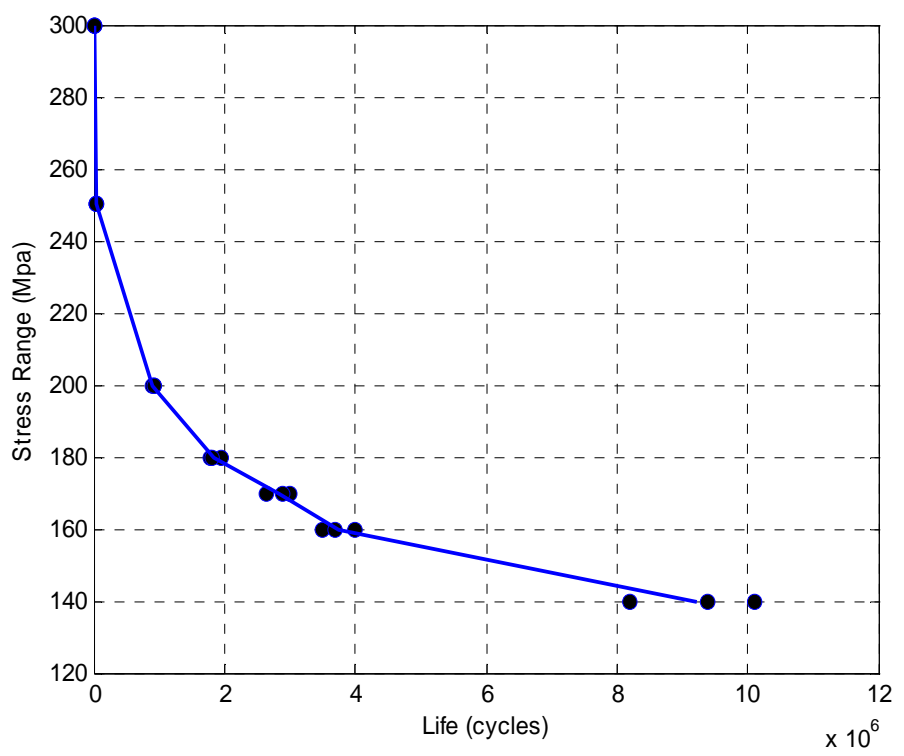

Figure 3. $(\mathrm{S}-\mathrm{N})$ curve for $2024 \mathrm{AL}$ - Alloy material for dry fatigue

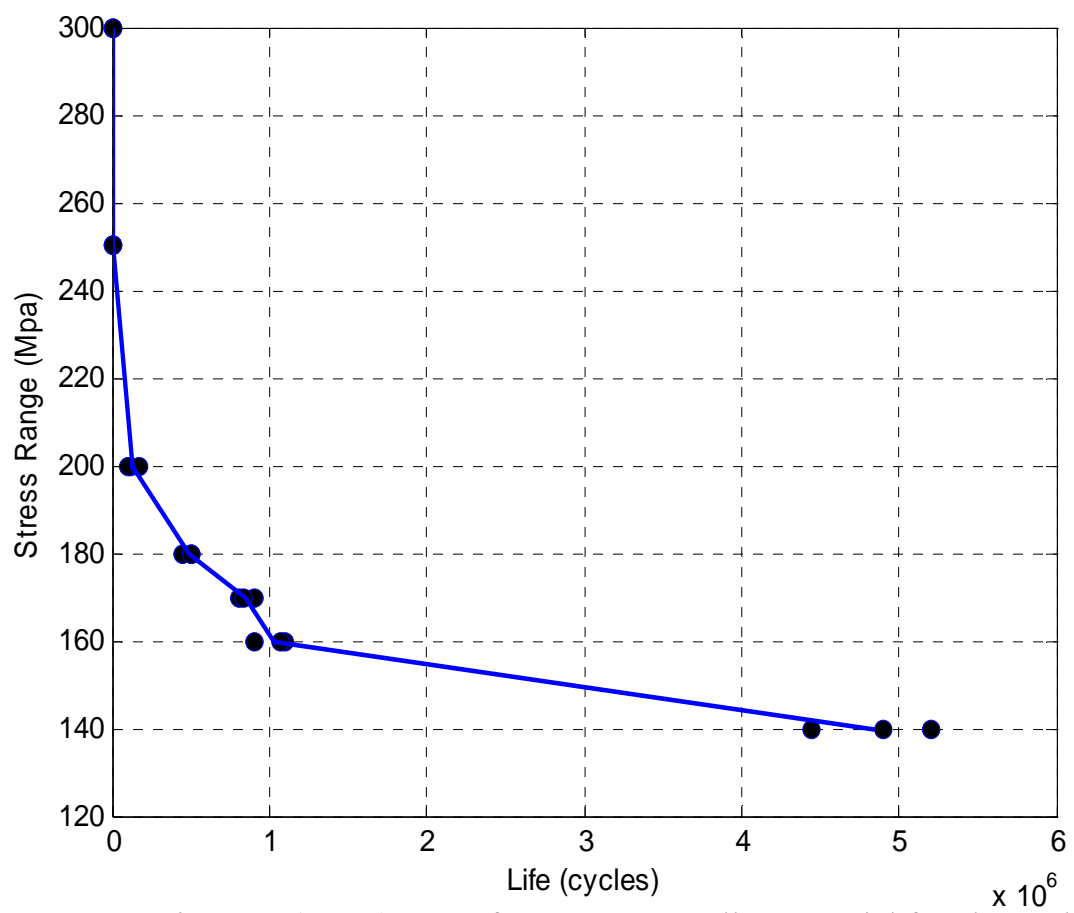

Figure 4. $(\mathrm{S}-\mathrm{N})$ curve for $2024 \mathrm{AL}-$ Alloy material for elevated fatigue 


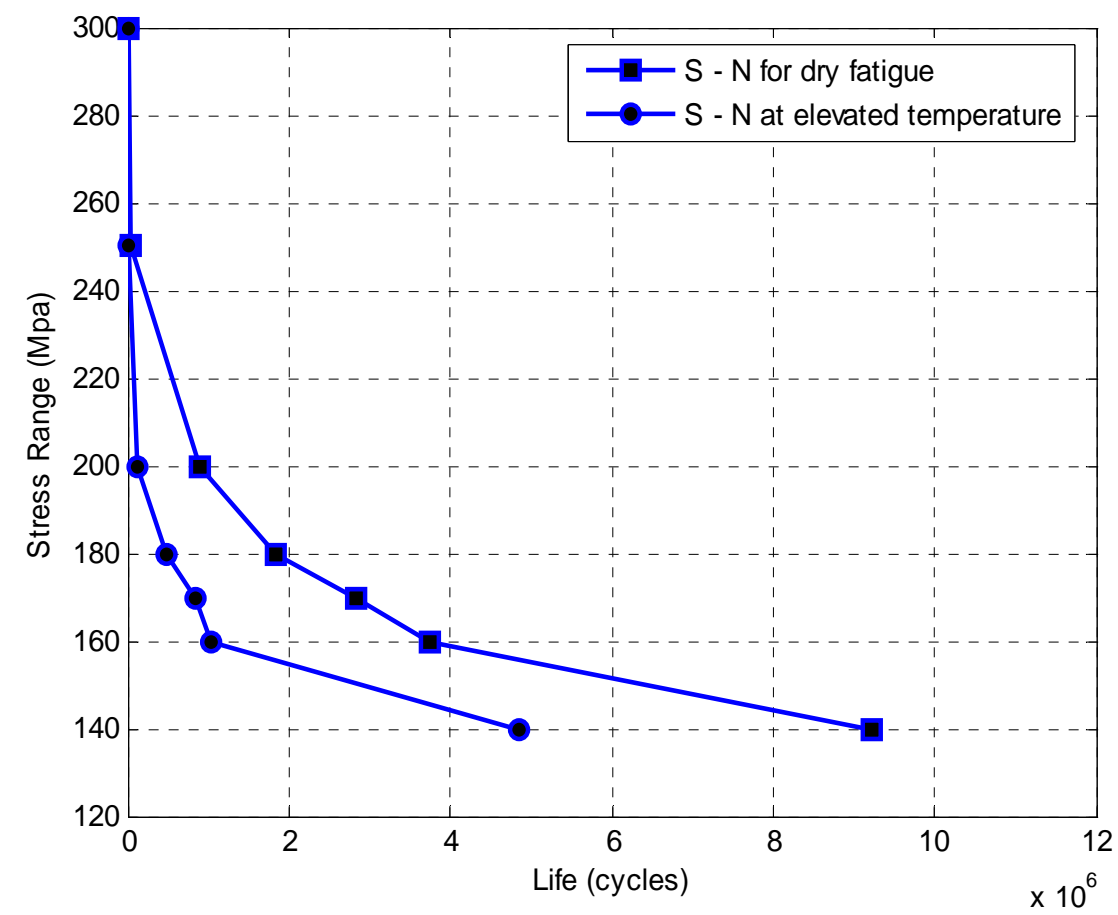

Figure 5. Comparison between the $\mathrm{S}-\mathrm{N}$ curve for dry fatigue and elevated temperature

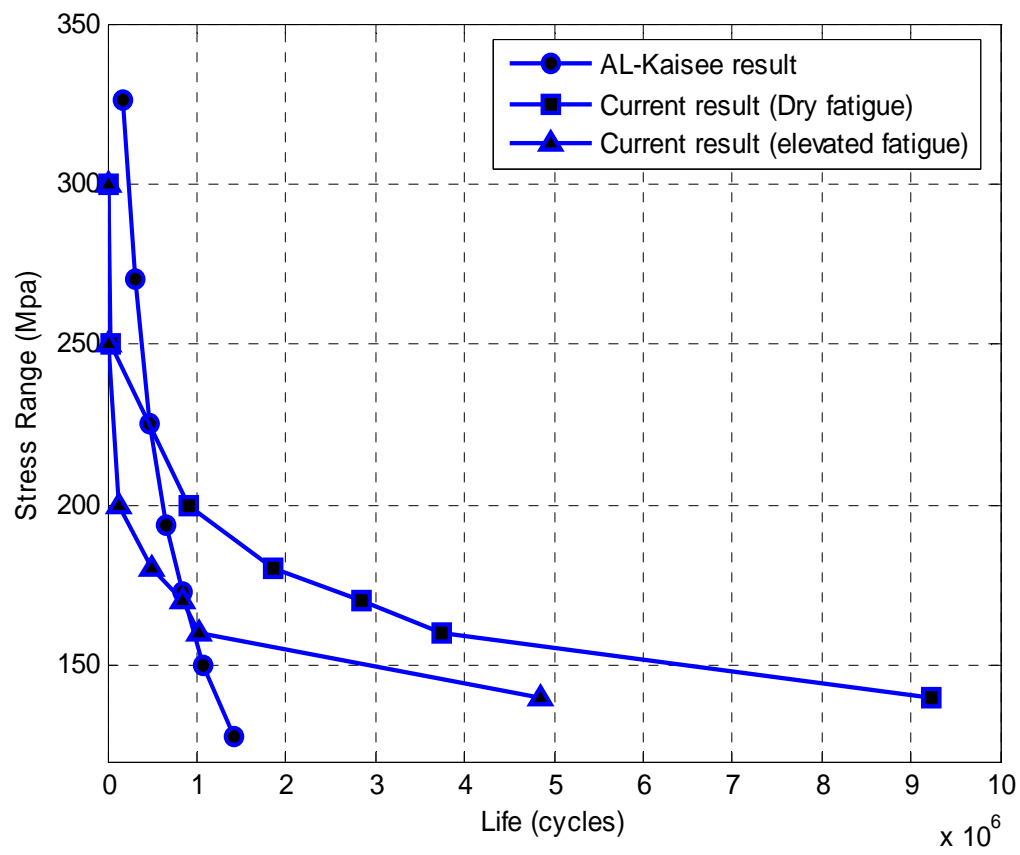

Figure 6. Comparison between present results and $\mathrm{AL}-$ Kaisee result 


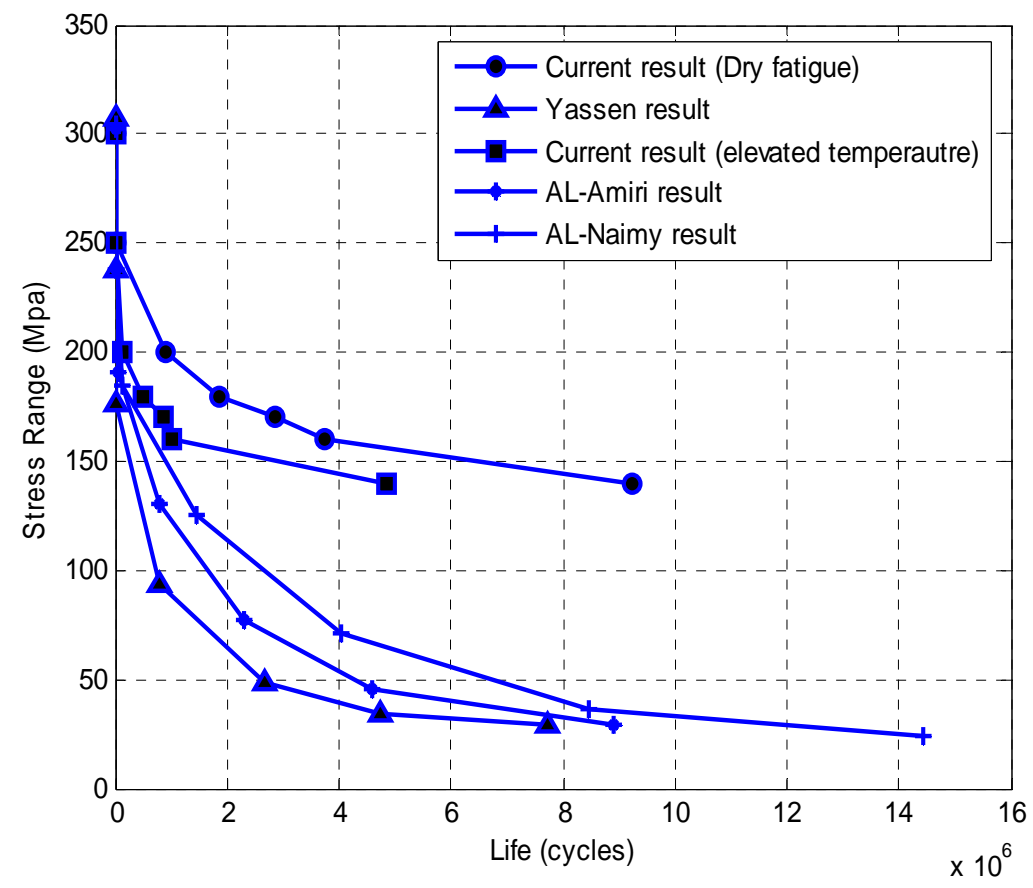

Figure 7. Comparison between present results and $\mathrm{AL}$ - Amiri, Yaseen, and $\mathrm{AL}$ - Naimy Results 